\title{
Research on the documentaries and carved inscriptions title in Chinese history
}

\author{
Zhihua Xu \\ College of Art Design, Jingdezhen Ceramic Institute, Jingdezhen, China
}

\begin{abstract}
Keywords: Inscriptions, Carved; Colophon; Inheritance
\end{abstract}
\begin{abstract}
The complete inseparable inscriptions carved credit, carved font text on the transfer to achieve the transfer of inscriptions font literature, and formed a permanent preservation of inscriptions art, history and culture of the Chinese widespread and long-term spread. Its large contribution but few people know , very few documented in the inscriptions in the title is also rare , and little is currently its researchers, giving research work has also brought some difficulties. Now I kind of inscriptions from the historical relics in the title Keke workers one by one classification , thus summed up developments and changes in inscriptions title .
\end{abstract}

\section{Introduction}

The stele inscriptions, refers to the word or pattern, most of the inscriptions written on paper with a brush, and then writing good ink replication in a flat stone ( or cliff ), and then through the carved engraved from. But some Cliff and Caves, often not by writing directly on the stone surface were carving knife. But no matter what methods are needed to complete the carving, so there have been many dynasties Jun engraved master. Both of these stone arts of calligraphy or its ornamentation on its subject carved on both the merits of the art. We know that usually belong to the second stone art works, its artistic merits of the level, not only in the quality of the original work, is more important is the level of carving skills. However, when performed on a stone art appreciation, people basically do not expect to know who is carving? Generally only will look who it is written. The reason: one is the art of calligraphy and profound human being to make known; the other hand, the few left in the inscriptions carved title. The author tries to based on rare literature and inscriptions in the agency attempts to develop a kind of carved the title of a preliminary analysis.

\section{Carving Title Development}

Carved on the stone generally do not leave your name, and some leave the name, and now the earliest known signature engraved on the stone work is Han Yuan and four years ( 117 ) " worship Excellencies Hill Monument" Song of carved high . Han Dynasty carved inscription written unnamed people even go down more than the emergence - Ye Qing Yi bud "stone recorded compensation" ( Volume XVII) says: " Hanbei book essays names and more vain , and when attached to the monument man -made monument end, such as " stone by the Analects of Confucius" workers Tran Hung , ...... . " in addition, the Han Dynasty has been a " material Le Gong Ming , "the system, the establishment of such a system is to facilitate the assessment of carving skills , urging carved engraved name by improving skills in order to implement incentives. Inscriptions carved signature in the Han dynasty after intermittent, " Wu Le Gong name " system did not continue the evolution, in the Wei and Jin stone carving signer on few, especially in the epitaphs title and no, this is probably taboo and funeral customs in his own name written underworld relevant, even in extremely flourished during the Northern Dynasties statues are also rare. However, to the Tang and Song dynasties gradually increased, especially after the Song, folk there have been many special lettering workshops, they often question the Department on the stone carved names, some also question the workshop name. To the Ming and Qing Dynasties , the official title is engraved in carved and uncommon, especially Kangxi, Qianlong period, two emperors left many of Yushu stone, which has a carved stone have no title . Carved in stone on a no 
title reflects the authorities do not attach importance to the carved and engraved signature process; on the other hand also reflects theengraved craftsmen's low social status.

\section{Development and Changes in the Way Carved Title}

Carved same title as the book 's title, because due to time vary, each with distinct characteristics, and even there are also differences between different identities, usually every age there is also a big difference .

Earlier we talked about carving title comes from the Eastern Han Dynasty , the Han Dynasty carved Colophon generally call themselves " workers", such as carved " worship Excellencies Hill Monument" Song Gao ; or " Carpenter ", such as carved "Wu Liang Temple monument," the guard changed ; or self-proclaimed " masonry " Such as engraved "Wu Liang Temple stone palace ," Meng Fu , Wu Mao , SUN Zong ; or claiming "monument division," as inscribed " Captain Han Sui China Bear monarch monument," the monument division Cheng Chung Ling Fu ; or claiming to be "made masonry ", such as carved " Berkshire prefect Fan Min monument" of Liu Sheng, etc. ; or self-proclaimed " rock division," Han Jianning five years ( 172 ) , " Fu Ge Song," signed " South Side stone division mouth mouth Wilmington ." Department above title to title "Stone division," the majority,

Such as the "Three Mountain Monument", "The Promise Hill Monument" , "Li Xi Fu Song," " Kong Dan Stele ", " Guiyang Prefecture weeks Fu Jun monument ", " Whitehead gods monument ", " Yongsan Song" etc. title Department for "Stone division ." The earliest use of " carving " is the word the first year of the Three Kingdoms Wu Xi (276 ) "Zen Mountain National Monument ," by Yin Zheng, He pardoned the two co- engraved, the Department is " carved ." However, there is little more than the title signature carved specific instructions specific work undertaken is made monument, statue or lettering, portraits , mostly termed general , only a small part of the problem in the Department of inscriptions engraved clear specific duties , such as Wu Liang Temple said stone masonry , "Meng Fu , Wu Mao made the Wuhou Temple stone palace, SUN Zong -made lions , wei Wu Liang Temple monument engraved change".

The southern and Northern Dynasties for the stone art development peak, but the undersigned carved is little. Occasional Colophon much self-proclaimed "rock division", there are questions department "carved", such as the Three Kingdoms Wu Xi first year ( 276 years), "Zen State Hill monument", the carved Yin Zheng. He pardoned himself "carving" ; also the title department " Carpenter monument ", such as Ming dynasty years ( 458 years ) ,"Cuan Longyan monument" is carved Du Chang child self-proclaimed" Carpenter monument".

Tang Dynasty Calligraphy has been a great development, because Li Shimin love of calligraphy, inscriptions, now that many of them are leaving their inscriptions, wrote the inscription, he often some famous calligrapher Zhao Ming written inscriptions, such as " Zang holy church order large monument " for the author himself ; " Confucius temple monument "is its Chizhi Yu Shinan relegated ; " Jiuchenggong yechon Ming " author Wei Zheng Feng Chi also relegated, the book Le Ouyang Xun Feng ; Some famous minister also issued an edict after the death of its author erected, such as Du Ruhui after the death of the emperor Shouzhao Yu Shinan its monumental . Another example is Zhang Ming Chen said after the death of Emperor also wrote the inscription for its famous calligrapher Liang Qing written up by the famous carved crane Wei Ling Publishing, which fully demonstrates the importance of the Tang Dynasty calligraphy and inscriptions . Especially since the emperor 's participation and attention, this time writing and inscribed inscription identity, status, and the former has been very different, people tend to be written and inscribed imperial imperial inscription as the highest honor, plus after the Tang epitaphs become funeral equipment, essays who book and inscribed by the ordinary sense in which the signature has become a common phenomenon . In addition to government offices carving, folk there are a lot of carving, and government offices carved been clearly rank positions, therefore , carving there are differences depending on the title of his office , and some said Lin Taiwan regular script Lingshi , and some said the straight will be monitored some called direct Calligraphists prison straight Division , and some said a long prison camp Calligraphists on , some said the secretariat 
carved jade book officer, said there are still parties prison ( less government supervision ) straight Division. As Wu Zhou Changan years ( 702 ), Chen Huaiyi carved " Li Yilin and Mrs. Westergren buried Epitaph" , on that signature "Shang Fang prison straight Division Juan word people ." When these government offices carved stone engraved titles tend to question the government offices, but there 's no question rank. And the popular folk carved engraved Birthplace. Above phenomena are to highlight their status, which is enough to see the status of the Tang Dynasty carved markedly improved, they are no longer considered a lowly occupation stone, but proud of it.

Tang Dynasty carved a name in the title of their own in addition to the continuation of the former Carpenter , masons, masonry and other titles, but also claimed to be lettering , Juan word , Juan Carpenter , lettering people, engrave the word people , etc. , as well as the self-proclaimed Stele people, carved like a man , man -made monument, built monument Dajiang, Dr. statues and so on. Large and medium-sized fourteen years ( 860 ) Wu Yan inscribed " Huating County startups France cloud Temple mind" , since the department " Most materials Carpenter" , late Tangru Nan Zhou $\mathrm{Ru}$ is carved from the department " most expected ." From these different titles can distinguish the difference between their status, as well as different skill differences stone division . Such as " Dajiang " skills and position slightly higher than the general craftsman , and statues of Dr. is highlighting its artistry background, Juan word people, lettering and other people are interested in highlighting its skill in calligraphy, stone people, statues persons whose skills are emphasized engraving materials. As for the " most material " and " most of the material Carpenter" is the equivalent of Dajiang level, its position above the " all material " and " all material Carpenter ."

Song carved Colophon addition to the regular carpenter , mason , stone works , masonry and other questions Department , also followed the former 's " are expected ", " dirty ", " mason for the head " and the title department, appellation government offices carving of generally Royal College applicable only to designate, jade books books provincial government, less government supervision officer jade book , Imperial jade book book arts bureau official , Dai Zhao , Ying Feng Yu book Imperial officer and so on. In addition, there have been three new title Department , one called " hermit " , so-called " hermit " has the meaning " Recluse " and, carved as a way to explain their literati as cultural accomplishment ; II said as " jade carving ", " jade ", " Yu Jiang ," " jade workers" and so on, such as yuan Dade five years ( 1301 ) Ma Yan Wen inscribed " cave shrine inscriptions" , the self- department " jade carving ", and positive for three years ( 1343 ) September Wang Wen inscribed " responded rebuilt Temple in mind," the self- title " jade workers" , and as to shun four years ( 1333 ) Chang Lin , Chang Xuan, etc. carved "Zou County Meng Temple Sage forty V Sun Mengning tombstone " on it since the title " Yu Jiang " This title contains praise from the surface to understand the meaning of jade stone of the material is essentially carved their own improvement. Of the band "Jade" Now that the word of the title is actually the beginning of the Tang Dynasty, such as Tang Dazhong four years ( 850 ) " seems to escape justice Epitaph" , the text at the end department " keep left before the declaration section leader Captain Wei long" on Juan " LI Zheng Yu official book lettering . " Such as Tang Dazhong fourteen years ( 860 ), " Joseph Lee real Epitaph" , the text at the end department " Juan Jade Palace Yin Chung San book lettering ." As Don Xiantong fourteen years ( 873 ) , " Liu Zhongli Epitaph" , the text at the end department " official Shao Yu book early engraved ." Another example Tang Qian Fu four years ( 877 ) " Zhoumeng Yao Epitaph" , the text at the end department " Yu Shi Lang book officer will try Lang Liu Chang Temple Law Society engraved age support " ; three called " open" and " open stone" or " open word "and so on, as Jiayou two years ( 1057 ) dolomite Chen Cheng Chuan title, engraved on the Department " monk should chi dickite . " Another example Xining three years ( 1070 ) June Liang inscribed " ningyang filial heavy Sutra" , which since the title "On the word of people ." ( 1033 ) May Luoyang Ming carved carvedDi Lingzhi years " righteous teacher to Luoyang Building ", which claims to be "on the word of people ."

Yuan carved followed the Song Dynasty from the department " Hermit ", " Recluse " , such as the famous carved Mao Shao of self- department " can Jingchu disabilities ", and the title department " open character who " is relatively rare , emerging Colophon there called " $\mathrm{Zi} \mathrm{"} \mathrm{。}$ Zhang Zai Germany inscribed as "forbidden Leather Fair colored mesh tablets" , the title 
department " Zhang Zi Juan Zaide book ." Another example Xuande years ( 1435 ) engraved "Reconstruction Watkins Hall tablets" , the monument engraved with " Juan word Carpenter von ceremony , Feng Rong ," and " Christine Zhao Zi " in the name . But also to imitate painting by using printed signature engraved forms, such as 21 years ( 1361 ) carved Huan Lu Yuan positive " state reconstruction Jiading Confucian mind," monument title department " rooftop Huan Lu " engraved name two map printed .

Ming and Qing carved Department followed the former title using the " stylus " title department , and continue to follow the engraving of the law, such as the Qing Dynasty carved " Jiaoshan put Crane map", the title department "Twenty- four bridges owner stylus ' name engraved " Wu Yusheng "Indian . Another example is the first year of Emperor Guangxu (1875 ) June engraved " Yuantong monument," the title department " Hermit Lu stylus too easily carved ." " health workers " that show the identity of the carved workers. Another example is the Chenghua 23 years ( 1487 ) Li Zhen engraved "rebuilt Kokokuji France dependents in mind," the self- department " Juan word Confucian ." Another example is the eight Yuan Hongzhi armor engraved " Miss ceremony Epitaph" , the self- department " Juan word with disabilities ."

From the development and changes over the dynasty carved the way Colophon we can see carved Colophon initially than popular , simple, affected the literati and the art of calligraphy title Department, exquisite carving often that carving and calligraphy art in one, they called the natural order of the elegant, some question the Department of the affected government offices when the system had to take the title Department official in the inscriptions , or even directly signed by an official .

\section{Conclusion}

Inscriptions carved Colophon affected by many factors, on the one hand, with the gradual maturation of art and inscriptions evolving ; hand, with the way the Department of carved position title change has also been a big difference. Even with the same dynasty, whose title department there are a lot of different ways , this change from when the change towards aesthetic culture , habits , preferences , etc. emperor . Song appeared as a band "Jade " word of the title department , which is popular with the Song Dynasty jade related Huizong jade because of excessive love, not only court preferences jade, folk ordinary citizens who have become appreciation of jade , owner, wearing jade by the majority of the public sectors and sought after by popular poets . Therefore, jade culture reached its peak in the Song Dynasty, jade pondering surge, courtesy of greatly reduced, and the emergence of the jade market and specialized shops selling jade , is in hot pursuit of jade , stone title Department Yi Yi "Jade " itself . Yuan popular title department "Recluse ", " Hermit " and so on , which is the pursuit of the Yuan Dynasty literati aesthetic and interest in life is not without relevance . Therefore, we can say that the development carved title is not easy, it is influenced by various aspects of horizontal and vertical elements.

\section{Acknowledgments}

Xu zhihua (1978-) design of the research direction of the art of Art: Design of art and ceramic art design. Presided over the Jiangxi Provincial Department of culture research project "Jingdezhen traditional culture of the construction industry in the ancient kiln landscape design research", code: YG2014177.

\section{References}

[1] Historical Museum of Northwest, 1953, "Ancient decorative pattern anthology ", The people of the northwest Publishing.

[2] Lihui Xu , Jun Zhen, 2010, "Decorative art of the Chinese moire", People's Fine Arts Publishing House.

[3] Zibing Tian, Shusheng Wu, Qing Tian, 2003, "Chinese pattern history", Higher Education Press. [4] Hongxiu Zhang, 1992, " The Tang Dynasty Epitaphs decoration selected”, Shan Xi People Art 
Press. 